\title{
The dimensionality of judgments of heaviness
}

ROBERT J. DONOVAN ${ }^{2}$ AND JOHN ROSS

UNIVERSITY OF WESTERN AUSTRALIA

Two groups of Ss judged differences in heaviness between all pairs of stimuli in three series of five weights each. One group judged differences in the 100-300 $\mathrm{g}$ range, the other group iudged differences in the $700-900 \mathrm{~g}$ range. The three series of weights in the two ranges consisted of one series of constant size varying in both weight and density, one series varying only in weight, and one series varying only in density. Multidimensional scaling analysis revealed at least two dimensions, and indicated that where both weight and density are allowed to vary, both will affect judgment of the magnitude of differences in heaviness. With heavier weights, density appears to exert an increasingly important influence on judgments of heaviness. Predictions from Ross and Di Lollo's vector theory were confirmed.

In normal psychophysical experiments $S$ is required to make judgments with respect to an attribute like heaviness, pitch, or brightness, with no special instruction about its definition. Normal psychophysical treatments of the results of such experiments assume that it is proper to treat judgments as if they were determined by values on a single dimension, that is, by scalar quantities representing subjective magnitudes.

Ross and Di Lollo (1968) have proposed a model that assumes that judgments of heaviness are determined by more than one stimulus characteristic. The model assumes that stimulus objects are represented by compound vectors in a multidimensional attribute space, and that heaviness is differently defined within the space for different collections of stimulus objects. Ross and Di Lollo (1968) based their argument on the results of judgment of heaviness with different standards and under conditions of shift.

Judgments of difference in heaviness should produce a structure under multidimensional scaling (MDS) analysis that is unidimensional if each $\mathrm{S}$ bases his judgments on a scalar quantity for each stimulus, but that is multidimensional if each pair of stimuli judged changes the definition of heaviness, as would be implied by the model of Ross and Di Lollo (1968). It is important to note that average judgments of difference for a group of Ss will produce unidimensional structures when Ss derive differences from scalar quantities, even where Ss assign quite different values to given stimulus objects. A multidimensional structure will not be produced by variation between individuals in the definition of heaviness. It will be produced only if at least some Ss treat stimuli as multidimensional and define heaviness differently for different pairs of stimuli.

The study reported here was designed to determine whether judgments of difference in heaviness produce a multidimensional structure. Numerical estimation of differences in heaviness was required for sets of stimulus objects made up of three subsets varying in weight and density, in weight only, and in density only. For purposes of analysis, averaged numerical estimates of difference in heaviness were treated as interpoint differences, no intermediate distance model being employed. The MDS method used was a standard metric method treating distances as Euclidean.

\section{Stimulus Objects}

\section{METHOD}

Six series of five weights each were constructed from 2-in.
Table 1

Weight (W), Height (H), and Density (D) for each Stimulus Object in each Series

\begin{tabular}{|c|c|c|c|c|c|c|}
\hline \multirow{2}{*}{ Series } & \multirow{2}{*}{ Dimension } & \multicolumn{5}{|c|}{ Stimulus Objects } \\
\hline & & 1 & 2 & 3 & 4 & 5 \\
\hline $\mathbf{L}$ & $\begin{array}{l}W(\mathrm{~g}) \\
\mathrm{H}(\mathrm{cm}) \\
\mathrm{D}\left(\mathrm{g} / \mathrm{cm}^{3}\right)\end{array}$ & $\begin{array}{r}100.00 \\
8.00 \\
.62 \\
\end{array}$ & $\begin{array}{r}150.00 \\
8.00 \\
.93 \\
\end{array}$ & $\begin{array}{r}200.00 \\
8.00 \\
1.24 \\
\end{array}$ & $\begin{array}{r}250.00 \\
8.00 \\
1.55\end{array}$ & $\begin{array}{r}300.00 \\
8.00 \\
1.86\end{array}$ \\
\hline LVW & $\begin{array}{l}\text { W } \\
\text { H } \\
\text { D }\end{array}$ & $\begin{array}{r}100.00 \\
4.00 \\
1.24 \\
\end{array}$ & $\begin{array}{r}150.00 \\
6.00 \\
1.24 \\
\end{array}$ & $\begin{array}{r}200.00 \\
8.00 \\
1.24 \\
\end{array}$ & $\begin{array}{r}250.00 \\
10.00 \\
1.24 \\
\end{array}$ & $\begin{array}{r}300.00 \\
12.00 \\
1.24 \\
\end{array}$ \\
\hline LVD & $\begin{array}{l}\mathrm{W} \\
\mathrm{H} \\
\mathrm{D}\end{array}$ & $\begin{array}{r}200.00 \\
16.00 \\
.62\end{array}$ & $\begin{array}{r}200.00 \\
10.60 \\
.93 \\
\end{array}$ & $\begin{array}{r}200.00 \\
8.00 \\
1.24 \\
\end{array}$ & $\begin{array}{r}200.00 \\
6.40 \\
1.55 \\
\end{array}$ & $\begin{array}{r}200.00 \\
5.30 \\
1.86 \\
\end{array}$ \\
\hline $\mathbf{H}$ & $\begin{array}{l}\text { W } \\
\text { H } \\
\text { D }\end{array}$ & $\begin{array}{r}700.00 \\
8.00 \\
4.32 \\
\end{array}$ & $\begin{array}{r}750.00 \\
8.00 \\
4.63\end{array}$ & $\begin{array}{r}800.00 \\
8.00 \\
4.94 \\
\end{array}$ & $\begin{array}{r}850.00 \\
8.00 \\
5.25\end{array}$ & $\begin{array}{r}900.00 \\
8.00 \\
5.56\end{array}$ \\
\hline HVW & $\begin{array}{l}\text { W } \\
\mathbf{H} \\
\mathrm{D}\end{array}$ & $\begin{array}{r}700.00 \\
7.00 \\
4.94\end{array}$ & $\begin{array}{r}750.00 \\
7.50 \\
4.94\end{array}$ & $\begin{array}{r}800.00 \\
8.00 \\
4.94\end{array}$ & $\begin{array}{r}850.00 \\
8.50 \\
4.94\end{array}$ & $\begin{array}{r}900.00 \\
9.00 \\
4.94\end{array}$ \\
\hline HVD & $\begin{array}{l}\text { W } \\
\text { H } \\
\text { D }\end{array}$ & $\begin{array}{r}800.00 \\
9.14 \\
4.32\end{array}$ & $\begin{array}{r}800.00 \\
8.53 \\
4.63\end{array}$ & $\begin{array}{r}800.00 \\
8.00 \\
4.94\end{array}$ & $\begin{array}{r}800.00 \\
7.52 \\
5.25\end{array}$ & $\begin{array}{r}800.00 \\
7.10 \\
5.56\end{array}$ \\
\hline
\end{tabular}

Note: Group $L$ made judgements of differences in heaviness for all pairs within the set made up of Series $L$, Series $L V W$ and Series $L V D$. Group $H$ made judgements for all pairs within the set made up of Series $H$, Series $H V W$ and Series HVD. The existence of the separate Series was not pointed out to $S s$ in the experiment.

aluminum tubing sealed at both ends with aluminum discs. Variations in heaviness were obtained by symmetrically placed cylindrical metal inserts glued inside each weight so as to minimize bottom heaviness and other inertial characteristics. There were three series of light weights and three series of heavy weights. Within the light set, the stimuli in the first series (Series L) varied with respect to both weight and density; the second series (Series LVW) varied only in weight; and the third series (Series LVD) varied only in density. Uniformity in density was obtained by varying the height of each stimulus object as shown in Table 1, which gives the relevant dimensions for each stimulus object in each of the series mentioned above as well as for the corresponding series (H, HVW, HVD) from the heavy set. It was expected that the VW and VD series would delineate the dimensions of weight and density in the two ranges.

\section{Subjects and Procedure}

Sixteen students chosen haphazardly from a senior psychology class at the University of Western Australia were allocated randomly to two groups of eight Ss each. The Ss in Group L judged differences between all pairs of stimuli within Series $L$, $L V W$, and LVD, and the Ss in Group $H$ judged pairs within Series $\mathrm{H}, \mathrm{HVW}$, and HVD. At the beginning of the experimental session each $S$ was seated at a table facing $E$ and was read the following instructions:

"You will be presented with a series of weights. The weights will be presented in pairs. Each time I put a weight in your hand I would like you to look at it while lifting it once and then put it down. You should lift the weight with a motion of the hand and 
Table 2

Average judgements of differences in heaviness for Group $L$ (above diagonal) and Group $H$ (below diagonal). The separate Series are designated as follows: Series $L$ and H-1, 2, 3, 4, 5; Series LVW and HVW-6, 7, 3, 8, 9; Series LVD and HVD-10, 11, 3, 12, 13 .

Stimulus Objects

\begin{tabular}{|c|c|c|c|c|c|c|c|c|c|c|c|c|c|c|}
\hline & & 1 & 2 & 3 & 4 & 5 & 6 & 7 & 8 & 9 & 10 & 11 & 12 & 13 \\
\hline & 1 & & 59 & 118 & 145 & 200 & 64 & 86 & 131 & 172 & 65 & 93 & 112 & 143 \\
\hline & 2 & 27 & & 80 & 111 & 187 & 46 & 38 & 92 & 159 & 42 & 48 & 110 & 116 \\
\hline & 3 & 34 & 27 & & 79 & 146 & 98 & 49 & 79 & 104 & 81 & 35 & 41 & 66 \\
\hline & 4 & 46 & 32 & 30 & & 68 & 164 & 123 & 72 & 48 & 106 & 91 & 84 & 44 \\
\hline & 5 & 49 & 42 & 35 & 26 & & 197 & 174 & 106 & 67 & 168 & 172 & 124 & 106 \\
\hline & 6 & 23 & 26 & 28 & 38 & 46 & & 56 & 122 & 157 & 54 & 67 & 86 & 98 \\
\hline Stimulus & 7 & 27 & 24 & 28 & 29 & 41 & 19 & & 81 & 159 & 49 & 42 & 87 & 115 \\
\hline Objects & 8 & 35 & 32 & 24 & 30 & 32 & 31 & 26 & & 67 & 98 & 72 & 80 & 57 \\
\hline & 9 & 49 & 40 & 36 & 31 & 23 & 36 & 41 & 32 & & 135 & 115 & 66 & 72 \\
\hline & 10 & 28 & 22 & 24 & 29 & 33 & 25 & 25 & 33 & 31 & & 46 & 78 & 114 \\
\hline & 11 & 34 & 28 & 24 & 31 & 30 & 26 & 26 & 27 & 30 & 27 & & 85 & 57 \\
\hline & 12 & 31 & 30 & 27 & 27 & 33 & 25 & 25 & 29 & 27 & 30 & 24 & & 53 \\
\hline & 13 & 43 & 34 & 26 & 31 & 32 & 41 & 30 & 25 & 31 & 35 & 25 & 20 & \\
\hline
\end{tabular}

wrist only, leaving your forearm resting on the table.

"I would like you to judge the difference between the pair of weights, but in doing this I do not want you to use ounces, or pounds, or grams, or any other standard measure of weight. Instead I would like you to use numbers. To begin with, I will give you one single weight which you will call 100. After having judged the first single weight, all other weights will be presented in pairs. You are to judge the difference between the two weights in each pair. If the difference is twice as great as the heaviness of the first weight, you should say 200 , and if it is half as great you should say 50, and so on. Your judgement of the difference between the weights in each pair should be proportional to the first weight. Do not hesitate to use numbers such as 72 or 217 and so on if they are the ones which best describe your judgement of the difference.

"Remember: You will judge one single weight and then many pairs of weights. You will call the first weight 100, and you should then judge the difference between the two weights in each subsequent pair in terms of the very first weight, which you called 100. You should look at each weight as you lift it."

The standard stimulus for Group $L$ was the middle stimulus object in Series $L$ that was common to Series $L, L V W$, and LVD (Table 1). The standard stimulus for Group $\mathrm{H}$ was the middle stimulus in Series $H$.

Since the middle stimulus was the same in each series within the light and the heavy stimulus set (Table 1), there were 13 different stimuli yielding 156 ordered comparisons within the three serjes in each set. Each $S$ made all 156 judgments in the relevant set in a random sequence that was separately determined for each $S$ by a PDP-6 digital computer. During the testing session all stimulus objects were out of S's sight except for the pair being judged.

\section{RESULTS}

The average judgments of difference in heaviness for Group $L$ and Group $\mathrm{H}$ are presented in Table 2.

Table 3

Fist Seven Latent Roots in Multidimensional Scaling Analysis for Each Group

\begin{tabular}{ccc}
\hline L & Group & H \\
\hline 7.650 & & 4.827 \\
1.307 & & 1.654 \\
0.931 & 1.551 \\
0.694 & & 1.128 \\
0.641 & & 0.846 \\
0.363 & & 0.778 \\
0.258 & & 0.762 \\
\hline
\end{tabular}

The latent roots resulting from the MDS analysis for each group are shown in Table 3. Both groups show a strong first dimension but at least one further dimension. The second dimension is stronger in Group $\mathrm{H}$ and, in addition, the structure seems to be complicated further by additional dimensions.

The 13 stimuli for the $L$ and $H$ groups are plotted in terms of projections on the first two dimensions in Figs. 1 and 2, respectively. Straight lines have been fitted through the $\mathrm{VW}$ and VD stimuli to show the dimension of weight and density. The important feature to note is that stimuli varying in both weight and density (VWD) follow a curvilinear path showing the effect of weight and density on judgments of differences in heaviness when both are allowed to vary.

\section{DISCUSSION}

Table 3 shows that judgments of the magnitude of differences in heaviness are based on more than one dimension, which implies that considerations other than weight intrude when the judgments are made. The fact that the stimulus series $L V W$ and LVD in Fig. 1 and HVW and HVD in Fig. 2 fall reasonably well along straight lines allows the identification of weight and density as separate dimensions for both the light and heavy stimuli.

The density dimension is more highly correlated with the weight dimension for light weight judgments than for heavy weight judgments. Density differences appear to be detectable within the light range, but to be confused with differences in weight. For heavy weights, differences in density are not only detectable, but less confused with weight. Density appears to exert an increasingly important influence on judgments of heaviness with heavier weights.

Whereas the VW and VD stimuli define single dimensions in Figs. 1 and 2, the VWD stimuli follow a curvilinear path in both cases, showing that where both weight and density are allowed to vary, both will affect judgment of the magnitude of difference in heaviness.

An informal subsidiary study with two Ss only suggests that judgments of the magnitude of differences in density also produce at least two-dimensional structures. The VWD stimulus series again follows a curved path, but in a space where the major dimension is defined by the VD series and the minor by the VW series.

The findings of this study generally confirm that judgments of heaviness are based on a representation of stimuli objects in terms of more than one dimension, and that density becomes more important in the heavier range. However, the situation may be more complicated than proposed by Ross and Di Lollo (1968), since at least three dimensions seem to be involved for the heavy stimuli in this study. Perhaps features such as size, inertial 


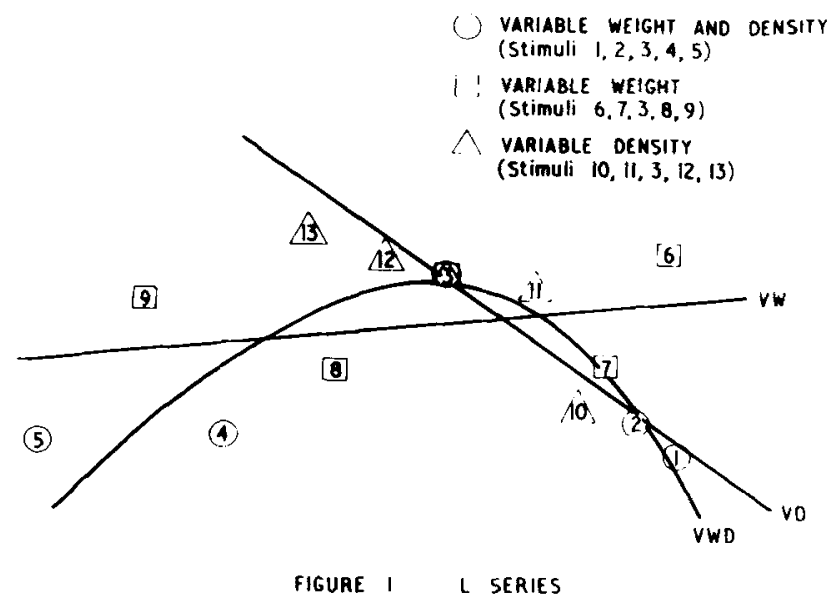

Plot of the 13 Stimuli on the first two dimensions

characteristics, and the judged emptiness and solidity of objects are other attributes that become relevant at various ranges.

\section{REFERENCE}

ROSS, J, \& DI LOLLO, V. A vector model for psychophysical ju dgement. Journal of Experimental Psychology Monograph Supplement, 1968, Vo. 77, No. 3, Part 2.

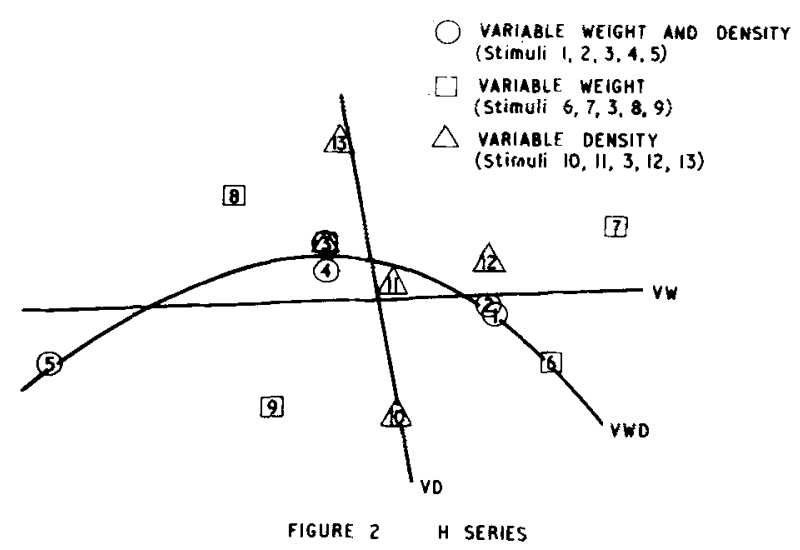

Plot of the 13 stimuli on the first two dimensions

\section{NOTES}

1. This research was mainly supported by the Australian Research Grants Committee under Grant No. ARG 15-226 to the second author. We acknowledge the help of V. Di Lollo in the design and execution of the study.

2. Address: Department of Psychology, University of Western Australia, Nedlands, Western Australia.

(Accepted for publication Febneary 23, 1969.) 